The Journal of Animal \& Plant Sciences, 31(4): 2021, Page: 998-1006

ISSN (print): 1018-7081; ISSN (online): 2309-8694

\title{
DIFFERENCES OF PHYSIOLOGICAL PARAMETERS AND SUCROSE METABOLISM IN BREAD WHEAT GENOTYPES EXPOSED TO DROUGHT STRESS
}

\author{
İ. Kutluํ, E. Turhan ${ }^{2}$, Ö. Yorgancilar ${ }^{3}$ and A. Yorgancilar ${ }^{3}$ \\ ${ }^{1}$ Eskisehir Osmangazi University, Faculty of Agriculture, Department of Biosystem Engineering, 26160 Eskisehir/ \\ TURKEY \\ ${ }^{2}$ Eskisehir Osmangazi University, Faculty of Agriculture, Department of Agricultural Biotechnology, 26160 Eskisehir/ \\ TURKEY \\ ${ }^{3}$ Transitional Zone Agricultural Research Institute, 26160 Eskisehir/ TURKEY \\ ${ }^{*}$ Corresponding author's email: ikutlu@ogu.edu.tr
}

\begin{abstract}
Twelve bread wheat genotypes were assessed for physiological parameters and sucrose metabolism for genotypic variations under drought stress condition. The field experiments were conducted 2013-2014 under irrigated and rain-fed conditions (having extremely dry conditions) to investigate the flag leaf area (FLA), flag leaf chlorophyll content (Chl), relative water content (RWC), loss of turgidity (LT), sucrose content, reducing sugars content, starch content, acid invertase activity (INV) and sucrose synthase activity (SS) in wheat genotypes. Although FLA, Chl, RWC and starch content decreased in all genotypes under drought conditions, LT generally increased, whereas sucrose content, reducing sugars content, acid INV and SS activities varied from genotype to genotype. Based on the results of Chl, RWC, and LT genotypes DH16, DH19 and Kate A-1 were relatively drought-tolerant genotypes. In addition, the genotypes DH16, DH18, DH19, Krasunia-Odeska and Syrena-Odeska adjusted their sucrose metabolism well when exposed to drought stress. Moreover, the genotypes DH19, DH21, Bezostaja-1 and Krasunia-Odeska regulated acid INV activity. The results suggest that $\mathrm{Chl}$, water status of the leaves, reducing sugars and acid INV activity could be an effective selection criterian of drought tolerance for wheat.
\end{abstract}

Key words: Acid invertase, soluble sugar, sucrose synthase, Triticum aestivum L., water deficit

\section{INTRODUCTION}

The principal food grain of Turkey, wheat is growing at the largest area of the country as well as worldwide under single crop. The wheat production is affected by cultivation under dry agricultural areas and marginal lands where limited, irregular precipitation creates water deficits. In prolonged drought conditions, as the water potential of the soil decreases, the stomata of leaves close, after which turgor pressure, leaf growth and the rate of photosynthesis decline, and ultimately, yield reduction occurs (Prasad et al., 2008). Water stress mostly affects the wheat grain yield during flowering and early grain-filling stages by causing either deteriorated pollination and fertilization or the abortion of grains (Barnabas et al., 2008). Reduced endosperm cell counts, carbohydrate supply and amyloplasts in the grain are the likely causes to no grain formation when wheat plants exposed water stress during pollination (Reynolds et al., 2016).

In semi-arid regions, wheat breeding for drought tolerance requires determination of the best selection criteria for drought-tolerant wheat genotypes (Saba et al., 2010). One potential criterion is the ability to preserve the rate of carbon assimilation during photosynthesis, which can sustain plant growth and production throughout dry periods (del Pozo et al., 2020). Other possible criteria include the chlorophyll content (Chl) in leaves, which affects the photosynthetic ability of plant tissues, and relative water content (RWC) in leaves, which when high lessens the elasticity of tissue cell walls and increases osmotic regulation ( $\operatorname{Rad}$ et al., 2013). Plants exposed to drought stress regulate their osmotic potential through accumulating organic solutions, organic acids, potassium and sugar alcohols in their cells to preserve turgor. However, the age of plants, especially during generative development, affects their osmotic regulation, which is slow before flowering but accelerates thereafter (Sanders and Arndt, 2012).

Another potential criterion for identifying drought-tolerant wheat is the higher heritable capacity of a plant genotype to store and translocate greater amounts of soluble sugars to grain, which has been positively associated with grain yield (Shearman et al., 2005; Ruuska et al., 2006) and thus proposed as a factor of increased tolerance to drought (Li et al., 2015). Soluble carbohydrates are a major source of the increase of organic solutions under drought stress and the accumulation of reducing and soluble sugars, especially sucrose. Sucrose protects mitochondria and other cellular components from the unfavourable impacts of drought, can forestall structural changes in soluble proteins and protects membrane phospholipids in the liquidcrystalline phase by acting as a substitute for water (Ruan $e t$ 
al., 2010). Monosaccharides support respiration and mitochondrial electron transport as respiratory substrates, which could counter the onset of dormancy and promote metabolism, energy production and the formation of oxygen radicals (Leprince et al., 2017). However, the role of reducing sugars in adapting to stress remains unclear. Bhattacharya and Kundu (2020) argued that their accumulation can harm plant tissues in various ways while Das et al. (2018) claimed that increase in soluble sugars under drought stress contribute to enduring the drought due to decreased sugar translocation, growth and starch hydrolysis. Cereals such as wheat use both carbons derived from photosynthetic assimilation and pre-stored carbohydrates from mature leaves for grain filling. After heading, if carbon obtained via photosynthetic accumulation remains low, then soluble sugars and starch in leaves play a significant role in compensating for the carbon supply to grain (Yang and Zhang, 2006).

Another pair of potential criteria for drought tolerance in wheat is the activities of the enzymes acid invertase (INV) and sucrose synthase (SS), which are closely associated with sucrose content. Whereas acid INV functions as a regulatory enzyme (Liu et al., 2014), SS plays a key role in seed maturation and abiotic stress tolerance by converting sucrose to starch (Zhang et al., 2020). Given those properties, both acid INV and SS could be worthwhile selection criteria for drought tolerance in wheat.

Drought tolerance has long been studied by both plant breeders and physiologists, some of whom have evaluated changes in the morphological (Bürling et al., 2013), physiological (Dwivedi et al., 2018), biochemical (Aidoo et al., 2017) and molecular (Kalaipandian et al., 2018) properties of wheat under drought stress. In addition, it was indicated in our previous study related to antioxidative enzyme activities that drought condition increased catalase (CAT) activity as compared with the control in wheat genotypes (Kutlu et al. 2017). However, because breeders seeking to improve the drought tolerance of wheat need to know how its genotypes differently regulate metabolic processes amid stress, it remains necessary to clarify variability in physiological changes and sucrose metabolism among wheat genotypes during stressful conditions. Accordingly, in the study reported here, changes in flag leaf area (FLA), Chl, RWC, loss of turgidity (LT), soluble sugar content and both acid INV and SS activity were formulated in the bread wheat genotypes during early maturity under field conditions exposed to drought stress.

\section{MATERIALS AND METHODS}

Agronomic practices and plant material: The study was conducted during the 2013-2014 crop season at the Faculty of Agriculture, Eskişehir Osmangazi University, Eskişehir, Turkey. The soil containing $1.38 \%$ organic matter and $5.8 \%$ lime, was unsalted $(0.08 \%)$, loamy and slightly alkaline $(\mathrm{pH}$ 7.8). Total twelve bread wheat genotypes including three Turkish bread wheat cultivars (Altay 2000, Müfitbey and Nacibey), four foreign-origin bread wheat cultivars (Bezostaja-1, Kate A-1, Krasunia-Odeska and SyrenaOdeska) and five doubled haploid (DH) wheat lines were used as genetic material. Bezostaja-1 (recommended for irrigated farming lands) was chosen as control cultivar (Öztürk and Aydın, 2017). The DH lines were developed from $F_{2}$ generations of hybrids of 33IBSWN-S-244, Tosunbey and Müfitbey in the Plant Tissue Culture Laboratory of the Transitional Zone Agricultural Research Institute in Eskişehir, Turkey. The experiment was designed in a split-plot design involving both irrigated and rain-fed conditions with three replications. Sowing was performed on 9 October 2013 in four rows with parcels $1 \mathrm{~m}$ in length and space between rows of $30 \mathrm{~cm}$. The amount of fertiliser used in irrigated plots was $90 \mathrm{~kg} \mathrm{ha}^{-1} \mathrm{~N}$ and $120 \mathrm{~kg} \mathrm{ha}^{-1} \mathrm{P}_{2} \mathrm{O}_{5}$, and $60 \mathrm{~kg} \mathrm{Nha}^{-1}$ and $60 \mathrm{~kg} \mathrm{ha}^{-1} \mathrm{P}_{2} \mathrm{O}_{5}$ in rain-fed plots.

In the case of precipitation, the study period was not an ideal growing season for wheat compared to long term climatic data. Although the total precipitation of longterm year of the experiment in Eskişehir was approximately $358.5 \mathrm{~mm}$, received quantity during the year of the experiment was very low with the value of $141.4 \mathrm{~mm}$ (Figure 1). Optimising yield and quality in wheat cultivation requires an average of 500-600 mm water, or at least 400 $\mathrm{mm}$. Wheat plants need the most water during stem elongation, heading and early periods of maturity, typically from March to May; however, those months in the year of the experiment experienced far less precipitation and higher temperatures than in last 30 years (Figure 1). In response to the extreme drought during the experiment, $300 \mathrm{~mm}$ of water were applied as irrigation reinforcements during stem elongation and early periods of maturity.

Flag leaves from early periods of maturity were used to analyse RWC, LT, sucrose content, reducing sugars content, starch content and both acid INV and SS activities. 


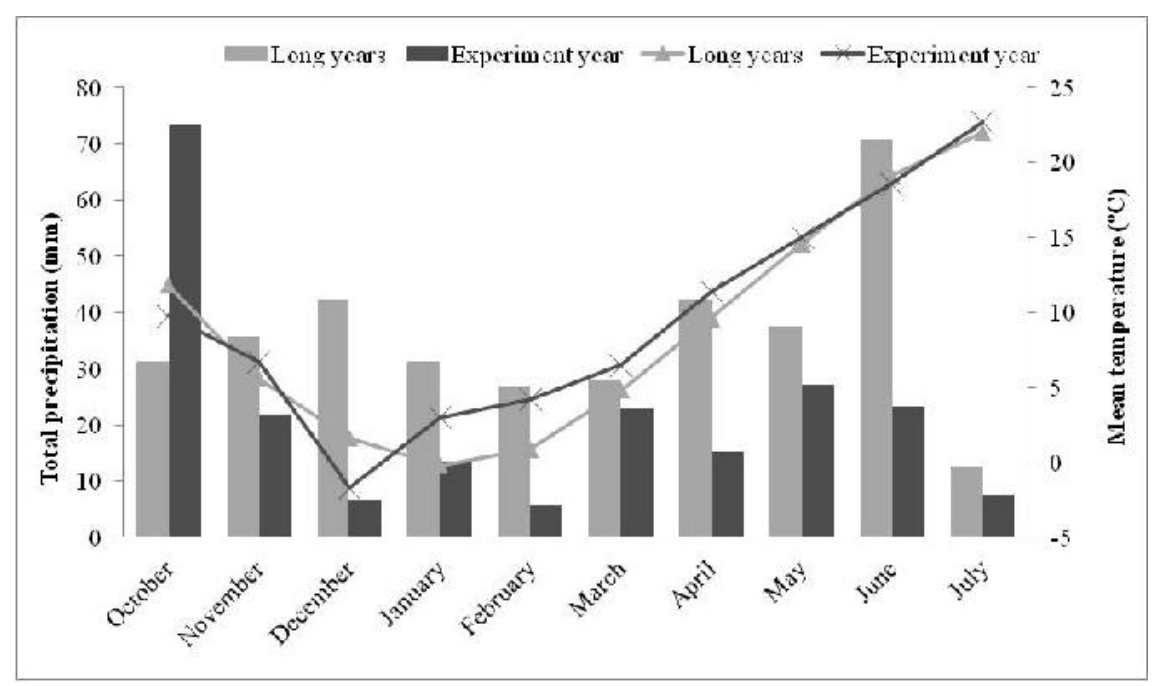

Figure 1. Total precipitation and mean temperature belong long term and experiment year in 2013-2014 growing season.

Flag leaf area and chlorophyll content: Flag leaf area (FLA) was calculated by multiplying the length and the width of each leaf by 0.75 , a specific coefficient for wheat (Kalayc1 et al., 1998), whereas Chl was measured using a chlorophyll meter (SPAD-502Plus, Konica Minolta), following Adamsen et al. (1999).

Leaf relative water content and loss of turgidity: Leaf RWC (\%) and LT were determined according to Gulen and Eris's (2003) method; the fresh weights (FW) of leaf discs $1.5 \mathrm{~cm}$ in diameter were weighed and released in distilled water in petri dishes for $4 \mathrm{~h}$, after which they were gently blotted, and their turgid weight (TW) was scaled. Thereafter, leaves were placed in an oven at $70^{\circ} \mathrm{C}$ for $24 \mathrm{~h}$, after which their dry weight (DW) was determined. Ultimately, RWC and LT were calculated by using the following formulas:

$$
\begin{gathered}
\mathrm{RWC}(\%)=[(\mathrm{FW}-\mathrm{DW}) /(\mathrm{TW}-\mathrm{DW})] \times 100 \\
\mathrm{LT}(\%)=[(\mathrm{TW}-\mathrm{FW}) / \mathrm{TW}] \times 100
\end{gathered}
$$

Soluble sugars: A method involving anthrone reagent, modified for determining non-reducing sugars content, was used to determine sucrose content (van Handel, 1968). First, a colourimetric estimation of reducing sugars content was performed with dinitrosalicylic acid (Miller, 1959), after which starch was detected by measuring glucose following the digestion of the ethanol-insoluble residue with amyloglucosidase (Dinar et al., 1983). For those measurements, the dried sugars were dissolved in $1 \mathrm{~mL}$ of distilled water. In collecting the solution, sugars were extracted by suspending $100 \mathrm{mg}$ of leaves in $5 \mathrm{~mL}$ of $80 \%$ (v/v) ethanol at $80{ }^{\circ} \mathrm{C}$ for $30 \mathrm{~min}$, after which the ethanolic solution was collected. After that procedure was repeated 4 times, the ethanolic solutions were merged and evaporated until dry at $55^{\circ} \mathrm{C}$ with the support of continuous ventilation (Turhan, 2012).
Acid invertase and sucrose synthase enzymes assays: The soluble (i.e. cytosolic) activity of acid INV in leaf tissue was determined by following method by Aloni et al. (1991). First, leaf samples totalling $500 \mathrm{mg}$ were ground in $5 \mathrm{~mL}$ of ice-cold, 25-mM HEPES (N2-2-ethane_sulphonic acid) buffer $\mathrm{pH} 7.2$, containing $5 \mathrm{mM}$ of $\mathrm{MgCl}_{2}, 2 \mathrm{mM}$ of DDT (DL-Dithiothreitol) and $3 \mathrm{mM}$ DIECA (diethyldithiocarbamic acid). Next, the mixture was centrifuged at $20,000 \mathrm{~g}$ for $20 \mathrm{~min}$ at $4{ }^{\circ} \mathrm{C}$, after which aliquots of $100 \mu \mathrm{L}$ of the supernatant were incubated in 10 $\mathrm{mL}$ of $0.1 \mathrm{~N}$ phosphate citrate buffer ( $\mathrm{pH} 5.0$ ) and $20 \mathrm{mM}$ sucrose at $37{ }^{\circ} \mathrm{C}$ for $30 \mathrm{~min}$. After that, $1 \mathrm{~mL}$ of dinitrosalicylic acid reagent was added, and the mixture was boiled for $5 \mathrm{~min}$. The resulting sugars were measured colorimetrically.

The SS activity was determined in method proposed by Aloni et al. (1996). First, following the same extraction procedure described for acid INV, the mixture was dialysed overnight to remove internal sugars. Next, enzymatic activity was determined as the breakdown of sucrose on aliquots of $200 \mu \mathrm{L}$ incubated in $0.1 \mathrm{M}$ of phosphate-citrate buffer ( $\mathrm{pH} 7.0$ ) containing $200 \mathrm{mM}$ of sucrose and $5 \mathrm{mM}$ of UDP (Uridine 5'-diphosphate). Following incubation at $37{ }^{\circ} \mathrm{C}$ for $30 \mathrm{~min}$, the resulting fructose was detected by a dinitrosalicylic acid reaction, and data were recorded as FW. Bradford (1976) assay was used to determine the total soluble protein content of the crude extracts.

Statistical analyses: Analysis of the variance (ANOVA) using the general linear model (GLM) to evaluate variation among genotypes and effects of application and the classification of genotypes according to Duncan $(\mathrm{P}<0.01)$ were performed using the IBM SPSS statistical package program (Version 20.0 for Windows, SPSS, Chicago, USA). 


\section{RESULTS AND DISCUSSION}

Variance analysis revealed the significant $(p<0.01)$ effects of application, genotype and genotype $\times$ application interactions on FLA, Chl, RWC, LT, reducing sugars content, starch content and both acid INV and SS activities. Although the application did not affect the sucrose content, differences among the genotypes and genotype $\times$ application interactions were significant (Table $1)$.

Table 1. Results of variance analysis (ANOVA) of genotype, application and their interactions with examined properties in flag leaves of bread wheat genotypes under drought stress. Numbers represent $F$ values at 0.01 level.

\begin{tabular}{lccc}
\hline & \multicolumn{2}{c}{ Independent variable } \\
\hline Dependent variable & Genotype & Application & Genotype x Application \\
\hline FLA & $15.80^{* *}$ & $4374.52^{* *}$ & $16.49^{* *}$ \\
Flag Chl & $16.82^{* *}$ & $977.17^{* *}$ & $19.87^{* *}$ \\
Leaf RWC & $22.07^{* *}$ & $627.22^{* *}$ & $12.19^{* *}$ \\
LT & $19.04^{* *}$ & $792.71^{* *}$ & $11.50^{* *}$ \\
Sucrose content & $7.25^{* *}$ & $0.15^{\text {ns }}$ & $5.84^{* *}$ \\
Reducing sugars content & $6.35^{* *}$ & $12.67^{* *}$ & $6.69^{* *}$ \\
Starch content & $38.09^{* *}$ & $569.18^{* *}$ & $38.09^{* *}$ \\
Acid INV activity & $31.25^{* *}$ & $74.11^{* *}$ & $29.29^{* *}$ \\
SS activity & $72.81^{* *}$ & $110.23^{* *}$ & $61.52^{* *}$ \\
\hline
\end{tabular}

${ }^{* *}$ Significant at $\mathrm{P}<0.01,{ }^{\text {ns }}$ Non-significant.

Flag leaf area, chlorophyll content, relative water content and loss of turgidity: Flag leaf area significantly increased among the genotypes depending on the application to irrigation (Figure 2a). In irrigated conditions, the Syrena-Odeska genotype gave the greatest FLA and the DH6 genotype followed it. However, the DH19 genotype had the smallest FLA, showing the least decrease when exposed to drought conditions. In drought conditions, the Müfitbey and Bezostaja-1 genotypes were prominent in terms of FLAs. Generally, a large leaf area contributes to yield of genotypes positively; however, based on the selecting approach for FLA in wheat breeding, broadleaved genotypes are preferable in places without water shortages, whereas narrow-leaved ones are the more appropriate in places with drought conditions (Fellahi et al., 2018). In that sense, genotype DH19, with its small FLA, can better resistant drought and heat.

Because flag leaves transfer $30-50 \%$ of photosynthetic assimilates to kernels during plant maturity (Abid et al., 2017), their photosynthesis is a significant factor of grain yield in wheat. In irrigated conditions, Chl ranged from 44.67 SPAD (DH19) to 57.73 SPAD (Krasunia-Odeska), whereas in drought conditions it varied between 19.97 SPAD (Nacibey) and 45.90 SPAD (DH16) (Figure 2b). Under drought conditions, genotypes DH16 and DH19 protected their Chl, whereas the genotypes Nacibey, Müfitbey, Bezostaja-1 and Krasunia-Odeska lost the most of Chl. Genotypes with high Chl, identifiable by their dark green colour, are desirable in wheat breeding to develop varieties for irrigated conditions. Higher Chl indicates a greater rate of photosynthesis, which is essential for high yields, and when water stress does not occur, stomata remain open for a long period to make photosynthesis. However, because genotypes with high Chl also have high canopy temperatures, which make them susceptible to drought in extremely arid areas, genotypes with low Chl may be advantageous for wheat breeding in arid areas (Reynolds et al., 2009).

Many researchers have proposed RWC as a good indicator for discriminating drought-tolerant genotypes (Bayoumi et al., 2008; Dwivedi et al., 2018). In the irrigated conditions, RWC changed between $74.96 \%$ (DH6) and $91.53 \%$ (Syrena-Odeska), whereas it peaked at $77.43 \%$ (DH16) under rain-fed conditions. Kate A-1 followed this line with $76.57 \%$ RWC value. Leaf RWC decreased under water stress in all examined genotypes (Figure 2c), likely due to decreased water supplies transported from the roots to the leaves that can occur when water reserves in the soil decrease. Other researchers have reported that the RWC of certain genotypes, which can deepen their roots and use soil water optimally or control water loss with stomata, are higher (Bayoumi et al., 2008; Hafez and Gharib, 2016); such genotypes, which protect their RWC under stress conditions, can sustain cell turgor and provide higher yields than genotypes with decreased water content. Genotypes could also accumulate solutions and metabolites as well as adjust their osmotic potential ( $\operatorname{Rad}$ et al., 2013). Loss of turgidity in the genotypes DH19, DH21 and Altay 2000 was approximately 30 to $35 \%$ in drought conditions yet was lowest, at nearly $16 \%$, in the genotypes DH16 and Kate A-1 (Figure 2d). As water stress suppresses cell development due to increased LT, leaf turgor pressure and total surface area reduce, which limits the photosynthetic capacity of flag leaves and ultimately lowers grain yield (Chaves et al., 2009). For that reason, it can be said that the genotypes 
DH16 and Kate A-1 are preferable for dry conditions due to their high RWC and ability to sustain turgor.
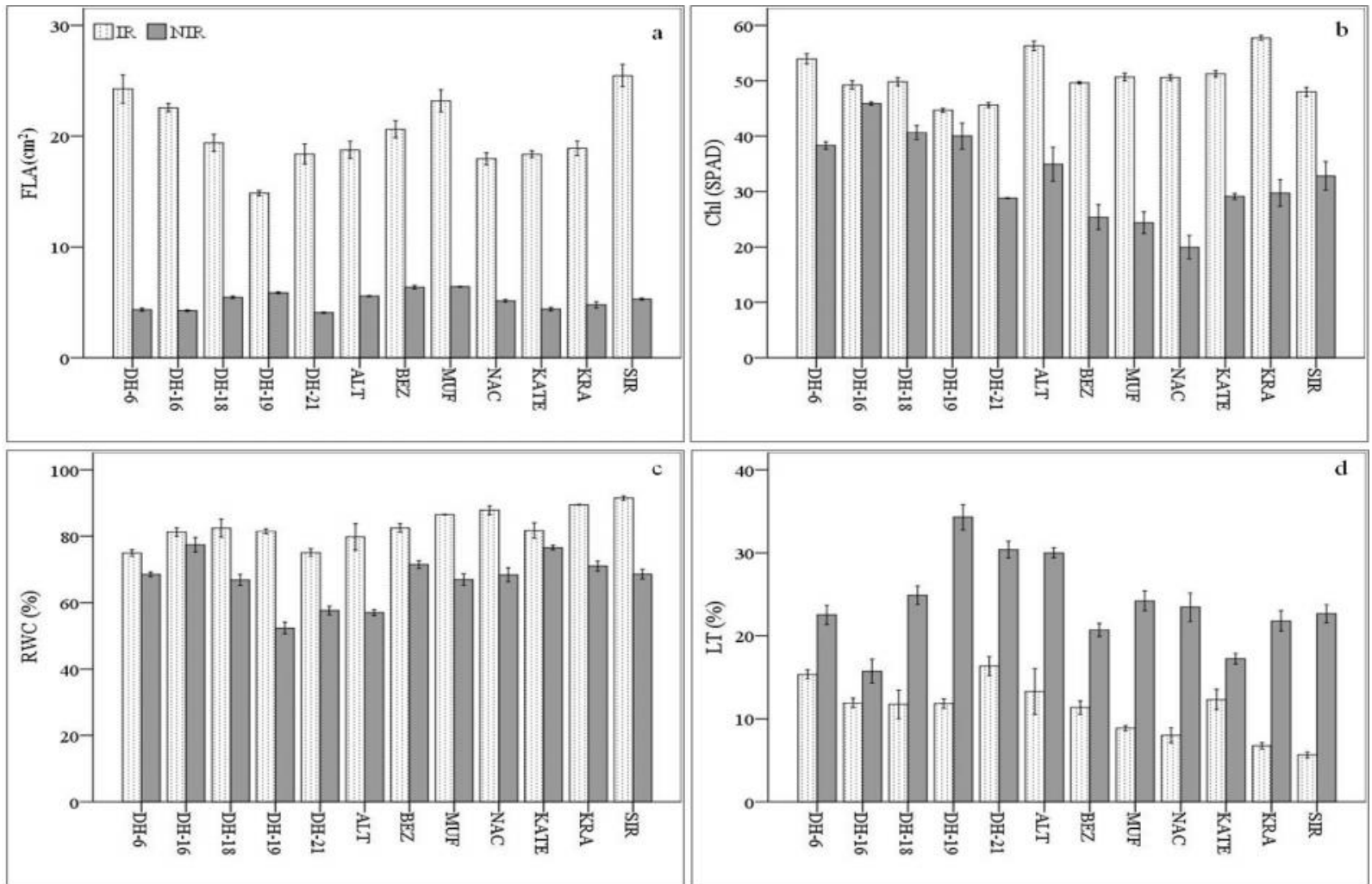

Figure 2. Flag leaf area (FLA) (a), flag leaf chlorophyll content (Chl) (b), leaf relative water content (RWC) (c) and loss of turgidity (LT) (d) of bread wheat genotypes under irrigated (IR) and non-irrigated (NIR) conditions. Error bars represent $\pm \mathrm{SE}$ of three replications.

Soluble sugars: Under stress conditions, sugars released in plants have properties that support plant growth and mitigate the adverse impacts of stress (Krasensky and Jonak, 2012). The ability of plants to maintain growth and development under drought stress can be measured by the accumulation of sugar in plant tissues; as indicators, low sugar content generally induces leaf senescence, while leaf yellowing accelerates amid a decreased rate of photosynthesis. By contrast, leaves with high sugar content also experience senescence as the transport of sugars to grain accelerates (Shi et al., 2016). Amid severe stress, total soluble sugar content generally increases in leaves (Ruan et al., 2010; Das et al., 2018; Khan et al., 2019). In drought conditions of the experiment reported here, sucrose content was variable in the genotypes (Figure 3a); however, the effects of application were not significant (Table 1). Such results suggest that sucrose content might be stable in drought conditions, which could prove vital for wheat under drought stress. Because stress depresses the rate of photosynthesis, stable sucrose content under drought stress may require plants to reduce their synthesis of starch and canalize carbohydrates to sucrose synthesis (Kondrák et al., 2012). In the experiment, drought stress caused in sucrose accumulation for only the genotypes DH21, Bezostaja-1, Müfitbey and Kate A-1. Besides, it was determined that DH6, DH19 and Altay 2000 maintained the sucrose content in drought condition. Sink tissues of plants represent the chief source of carbon and energy, not sucrose, which is transported by phloem to tissues for storage by being synthesised in the cytoplasm of leaves (Shi et al., 2016). Consequently, decreased sucrose in leaves might be transported to grain to compensate for the lack of carbohydrate supply due to a decrease in the rate of leaf photosynthesis during drought conditions.

For most genotypes, reducing sugars content was greater in dry conditions than in irrigated ones (Figure 3b). The greatest reducing sugars content occurred in the genotype DH18, followed by two other genotypes SyrenaOdeska and Krasunia-Odeska. Reducing sugars content of the genotypes DH6, Altay 2000, Müfitbey and Nacibey decreased in drought conditions. Such results suggest that the genotypes DH16, DH18, DH19, Krasunia-Odeska and Syrena-Odeska better tolerate drought than other genotypes in terms of the sucrose and reducing sugars contents in their leaves. Nemati et al. (2018) have reported that those contents increased in sensitive genotypes under drought 
stress; however, findings on that claim are contradictory. Most likely, the increase in reducing sugars content depends on the decrease of starch content (Figure 3c). Starch is a key molecule that, amid drought stress, seems to mediate plant responses to abiotic stress. If photosynthesis is limited under adverse environmental conditions, then plants generally remobilise starch to provide energy and carbon and it was reported that starch content in leaves decreased significantly as stress increased (Thalmann and Santelia, 2017). The results of the experiment reported here clearly indicated that starch content was quite low in drought conditions compared to irrigated ones (Figure 3).
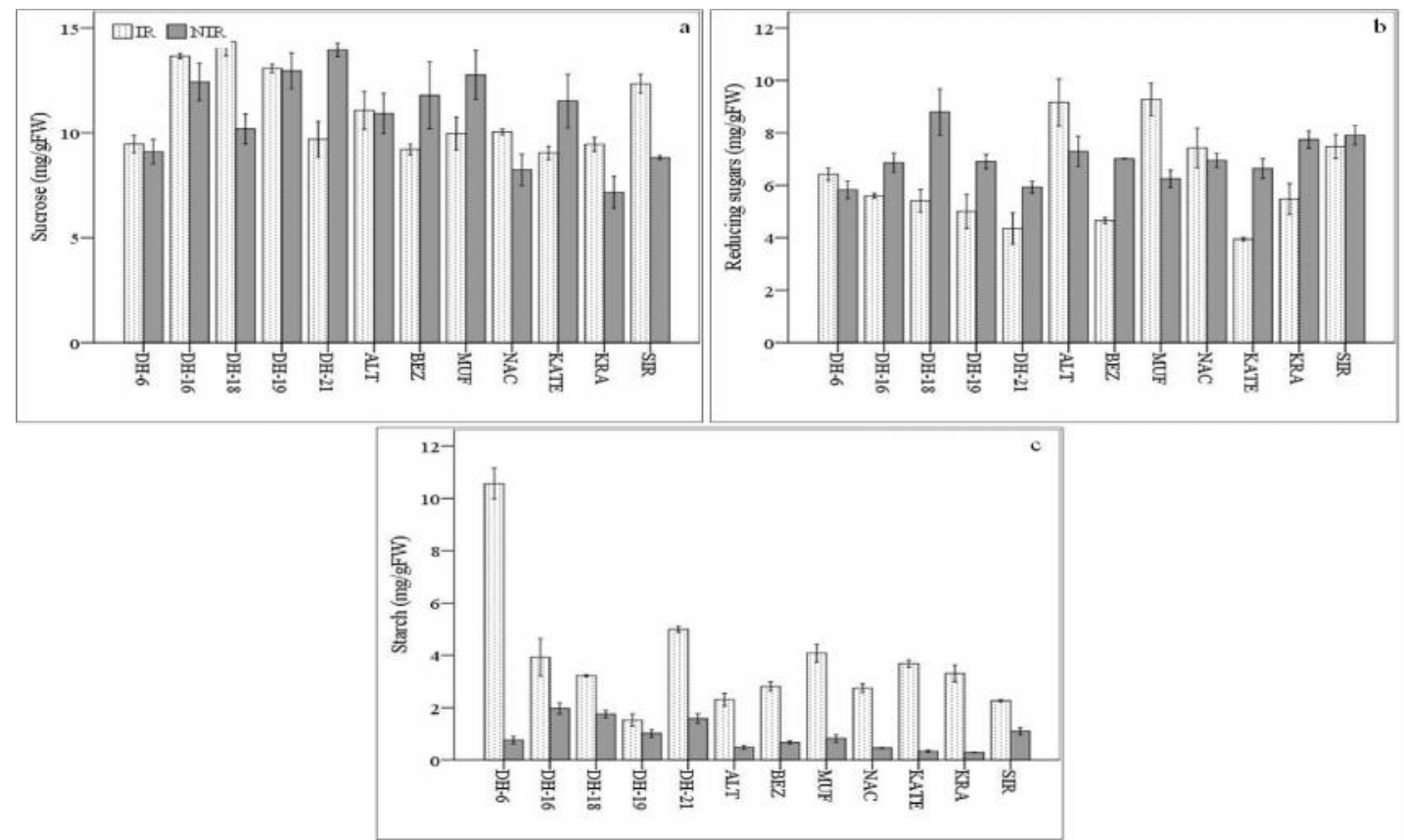

Figure 3. Sucrose (a), reducing sugars (b) and starch (c) contents of bread wheat genotypes under irrigated (IR) and non-irrigated (NIR) conditions. Error bars represent \pm SE of three replications.

In irrigated conditions, the genotype DH6 had the greatest starch content, whereas in drought conditions the genotype DH16 had the most. Interestingly, the genotype DH19, which had the lowest starch content in irrigated conditions, conserved its starch content in drought conditions. Starch degradation under stress in leaves is often associated with improved stress tolerance (Thalmann and Santelia, 2017), and most researchers who have examined carbohydrate metabolism in stress conditions have reported that leaf starch content decreased in response to abiotic stress (Villadsen et al., 2005; Damour et al., 2008; Sattar et al., 2020). Gonzalez-Cruz and Pastenes (2012), observing that a drought-resistant bean (Phaseolus vulgaris L.) variety degraded more starch than a drought-sensitive one, concluded that starch consumed in the bean's leaves accumulated in pods in response to drought stress. If such conclusions about leaf starch content under stress conditions can be extended, then it may be that all genotypes examined in the experiment reported here was drought tolerant.

Activities of acid invertase and sucrose synthase: Various enzymes associated with sugar metabolism engage in various reactions following sucrose transport and accumulation in tissues for storage. Acid INV regulates the sucrose accumulation of sink organs, especially during plant development, when it adjusts osmotic pressure and sugar signals in response to environmental changes (Koch, 2004). The acid INV activity in the genotypes DH19, DH2 1 and Krasunia-Odeska was greater in dry conditions, remained the same in the genotype Bezostaja-1 in both irrigated and dry conditions and rose in other genotypes exposed to irrigation (Figure 4a).

Sucrose synthase is responsible for synthesising sucrose in plant leaves and degrading it in sink tissues (Lu et $a l ., 2005)$. Higher SS activity in leaves reflects their ability to convert assimilates of photosynthesis into sucrose (Wang et al., 2015). In irrigated conditions of the experiment reported here, SS activity was greatest for the genotypes DH6 and DH16 and dramatically decreased in rain-fed conditions (Figure 4b).

However, for the genotypes Altay 2000, Bezostaja-1 and Syrena-Odeska it remained nearly identical in both conditions. In the genotypes DH21, Kate A-1, Müfitbey and Krasunia-Odeska, SS activity increased with drought, whereas in the genotypes DH18, DH19 and Nacibey, it increased with irrigation. The SS activity of the genotypes was generally compatible with sucrose content. Despite increased SS activity in the genotype KrasuniaOdeska, its decrease in sucrose content is noteworthy. In the 
case of drought, increased SS and acid INV activity may be protective; therefore, the genotypes DH21, Bezostaja-1 and
Krasunia-Odeska, which can maintain both activities in dry conditions, should be considered to be tolerant to drought.
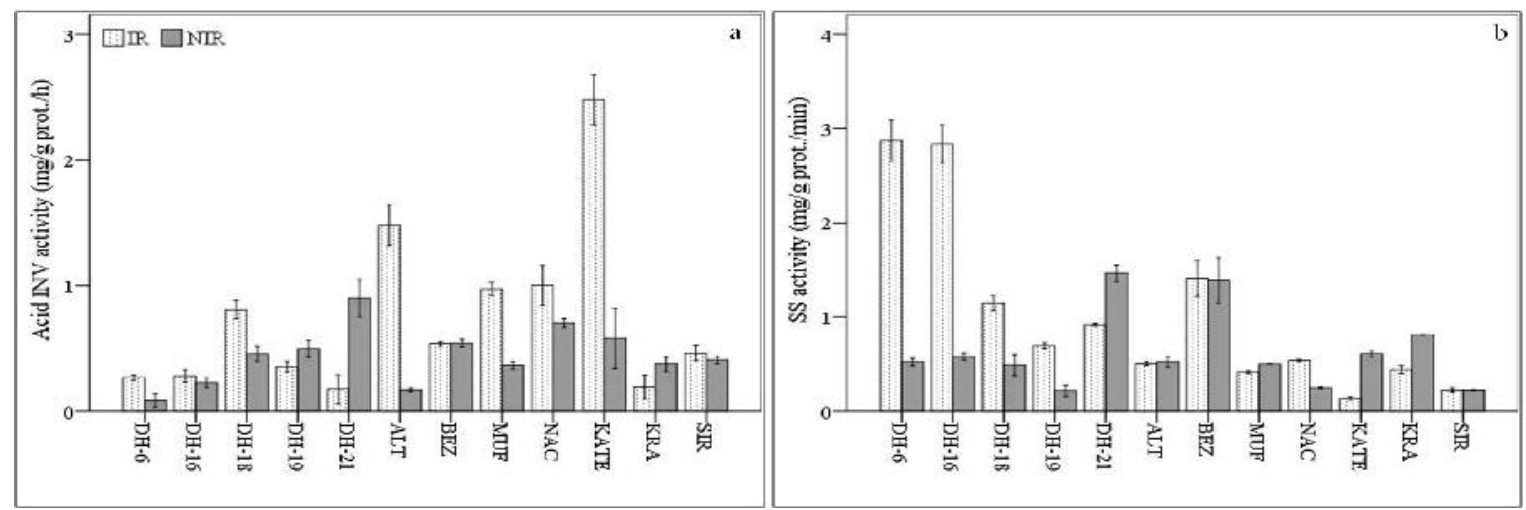

Figure 4. Acid invertase (INV) (a) and sucrose synthase (SS) (b) activities of bread wheat genotypes under irrigated (IR) and non-irrigated (NIR) conditions. Error bars represent \pm SE of three replications.

Conclusion: The characters examined in the study were found to be good criteria for identifying drought-tolerant genotypes in wheat. The genotypes DH16, DH19 and Kate A-1 were outstanding in terms of their physiological properties, whereas the genotypes DH16, DH18, DH19, Krasunia-Odeska and Syrena-Odeska adjusted their sucrose metabolism well when faced with drought. In addition, the genotypes DH19, DH21, Bezostaja-1 and Krasunia-Odeska might have protected acid INV activity associated with sucrose metabolism, which is a unique property of tolerance for wheat. Despite the fact that involved in drought tolerance of wheat plant, SS may not be related to the discrimination of genotypes.

Considering all of the features examined, the genotypes DH16, DH19, Bezostaja-1 and Krasunia-Odeska should be used to breed wheat with greater drought tolerance. The results of the study, performed under field conditions, can afford insights into the changing physiological properties and sucrose metabolism in wheat under drought condition. However, since other environmental factors may affect the trial results under natural conditions, the results should be also evaluated in molecular studies and trials conducted under controlled conditions.

\section{REFERENCES}

Abid, M., Y. Shao, S. Liu, F. Wang, J. Gao, D. Jiang, Z. Tian and T. Dai (2017). Pre-drought priming sustains grain development under post-anthesis drought stress by regulating the growth hormones in winter wheat (Triticum aestivum L.). Planta, 246(3): 509524.

Adamsen, F. J., P. J. Pinter, E. M. Barnes, R. L. Lamorte, G. W. Wall, S. W. Leavitt and B. A. Kimball (1999). Measuring wheat senescence with a digital camera. Crop ecology, production and management. Crop. Sci. 39: 719-724.

Aidoo, M. K., L. Quansah, E. Galkin, A. Batushansky, R. Wallach, M. Moshelion, D. J. Bonfil and A. Fait (2017). A combination of stomata deregulation and a distinctive modulation of amino acid metabolism are associated with enhanced tolerance of wheat varieties to transient drought. Metabolomics, 13(11): 138.

Aloni, B., T. Pashkar and L. Karni (1991). Partitioning of [14C] sucrose and acid invertase activity in reproductive organs of pepper plants in relation to their abscission under heat stress. Annals of Botany, 67(5): 371-377.

Aloni, B., L. Karni, Z. Zaidman and A. A. Schaffer (1996). Changes of carbohydrates in pepper (Capsicum annuиm L.) flowers in relation to their abscission under different shading regimes. Annals of Botany, 78(2): 163-168.

Barnabas, B., K. Jäger and A. Feher (2008). The effect of drought and heat stress on reproductive processes in cereals. Plant, Cell and Environment, 31(1): 1138.

Bayoumi, T. Y., M. H. Eid and E. M. Metwali (2008). Application of physiological and biochemical indices as a screening technique for drought tolerance in wheat genotypes. African J. Biotechnology, 7(14): 2341-2352.

Bhattacharya, S. and A. Kundu (2020). Sugars and Sugar Polyols in Overcoming Environmental Stresses. Protective Chemical Agents in the Amelioration of Plant Abiotic Stress: Biochemical and Molecular Perspectives, 71.

Bradford, M. M. (1976). A rapid and sensitive method for the quantitation of microgram quantities of protein utilizing the principle of protein dye binding. Analytical Biochemistry, 72(1-2): 248-254. 
Bürling, K., Z. G. Cerovic, G. Cornic, J. M. Ducruet, G. Noga and M. Hunsche (2013). Fluorescence-based sensing of drought-induced stress in the vegetative phase of four contrasting wheat genotypes. Environmental and Experimental Botany, 89: 5159.

Chaves, M. M., J. Flexas and C. Pinheiro (2009). Photosynthesis under drought and salt stress: regulation mechanisms from whole plant to cell. Annals of Botany, 103(4): 551-560.

Damour, G., M. Vandame and L. Urban (2008). Long-term drought modifies the fundamental relationships between light exposure, leaf nitrogen content and photosynthetic capacity in leaves of the lychee tree (Litchi chinensis). J. Plant Physiology, 165: 13701378.

Das, B., R. N. Sahoo, S. Pargal, G. Krishna, R. Verma, V. Chinnusamy, V. K. Sehgal, V. K. Gupta, S. K. Dash and P. Swain (2018). Quantitative monitoring of sucrose, reducing sugar and total sugar dynamics for phenotyping of water-deficit stress tolerance in rice through spectroscopy and chemometrics. Spectrochimica Acta Part A: Molecular and Biomolecular Spectroscopy, 192: 41-51.

del Pozo, A., A. M. Méndez-Espinoza, S. Romero-Bravo, M. Garriga, F. Estrada, M. Alcaíno, A. V. Camargo-Rodriguez, F. M. K. . Corke, J. H. Doonan and G. A. Lobos (2020). Genotypic variations in leaf and whole-plant water use efficiencies are closely related in bread wheat genotypes under well-watered and water-limited conditions during grain filling. Scientific Reports, 10(1): 1-13.

Dinar, M., J. Rudich and E. Zamski (1983). Effect of heat stress on carbon transport from tomato leaves. Annals of Botany, 51:97-103.

Dwivedi, S. K., A. Arora, V. P. Singh and G. P. Singh (2018). Induction of water deficit tolerance in wheat due to exogenous application of plant growth regulators: membrane stability, water relations and photosynthesis. Photosynthetica, 56(2): 478-486.

Fellahi, Z. E. A., A. Hannachi and H. Bouzerzour (2018). Analysis of direct and indirect selection and indices in bread wheat (Triticum aestivum L.) segregating progeny. International J.Agronomy, 2018.

Gonzalez-Cruz, J. and C. Pastenes (2012). Water-stressinduced thermotolerance of photosynthesis in bean (Phaseolus vulgaris L.) plants: the possible involvement of lipid composition and xanthophylls cycle pigments. Environmental and Experimental Botany 77: 127-140.

Gulen, H. and A. Eris (2003). Some physiological changes in strawberry (Fragaria $\times$ Ananassa cv.
'Camarosa') plants under heat stress. J Hort Sci and Biotech. 78:894-898.

Hafez, E. M. and H. S. Gharib (2016). Effect of exogenous application of ascorbic acid on physiological and biochemical characteristics of wheat under water stress. International J. Plant Production, 10(4): 579-596.

Kalaipandian, S., G. P. Xue, A. L. Rae, D. Glassop, G. D. Bonnett and L. C. McIntyre (2018). Overexpression of TaCML20, a calmodulin-like gene, enhances water soluble carbohydrate accumulation and yield in wheat. Physiologia Plantarum. https://doi.org/10.1111/ppl.12786.

Kalaycı, M., V. Özbek, C. Çekiç, H. Ekiz, M. Keser and F. Altay (1998). Determination of Drought Resistant Wheat Genotypes and Development of Morphological and Physiological Parameters in Central Anatolia Conditions, Eskisehir, Tubitak Research Project Final Report. Anatolian Agricultural Research Institute (in Turkish).

Khan, F. U., D. Fuentes, R. Threthowan, F. Mohammad and M. Ahmad. (2019). Comparative metabolite profiling of two wheat genotypes as affected by nitrogen stress at seedling stage. The J. Anim. and Plant Sciences, 29(1): 260-268

Koch, K. (2004). Sucrose metabolism: regulatory mechanisms and pivotal roles in sugar sensing and plant development. Curr. Opin. Plant. Biol. 7: 235 246.

Kondrák, M., F. Marincs, F. Antal, Z. Juhász and Z. Bánfalvi (2012). Effects of yeast trehalose-6phosphate synthase 1 on gene expression and carbohydrate contents of potato leaves under drought stress conditions. BMC Plant Biology, 12(1): 74 .

Krasensky, J. and C. Jonak (2012). Drought, salt, and temperature stress-induced metabolic rearrangements and regulatory networks. J. Experimental Botany, 63: 1593-1608

Kutlu, İ., E. Turhan, Ö. Yorgancilar and A. Yorgancilar (2017). Changes in Yield Components and Antioxidant Enzyme Metabolism of Wheat Genotypes in Drought Stress. KSU J Nat Sci. 20 (SI): 273-277 (in Turkish).

Leprince, O., A. Pellizzaro, S. Berriri and J. Buitink (2017). Late seed maturation: drying without dying. J. Experimental Botany, 68(4): 827-841.

Li, W., B. Zhang, R. Li, X. Chang and R. Jing (2015). Favorable alleles for stem water-soluble carbohydrates identified by association analysis contribute to grain weight under drought stress conditions in wheat. PLoS One, 10(3): e0119438.

Liu, Y., Y. D. Nie, F. X. Han, X. N. Zhao, B. Q. Dun, M. Lu and G. Y. Li (2014). Allelic variation of a soluble acid invertase gene (SAI-1) and development of a functional marker in sweet sorghum [Sorghum 
bicolor (L.) Moench]. Molecular Breeding, 33(3): 721-730.

Lu, H. Q., F. F. Shen, L. X. Liu and W. F. Su (2005) Recent advances in study on plant sucrose synthase. Chin Agric Sci Bull. 21:34-37

Miller, G. L. (1959). Use of dinitrosalicylic acid reagent for determination of reducing sugar. Analytical Chemistry 31(3): 426-428.

Nemati, F., F. Ghanati, H. A. Gavlighi and M. Sharifi (2018). Comparison of sucrose metabolism in wheat seedlings during drought stress and subsequent recovery. Biologia Plantarum, 62(3): 595-599.

Öztürk, A., M. Aydin (2017). Physiological characterization of Turkish bread wheat genotypes for resistance to late drought stress. Turkish J. Agriculture and Forestry, 41(6): 414-440.

Prasad, P. V. V., S. A. Staggenborg and Z. Ristic (2008). Impacts of drought and/or heat stress on physiological, developmental, growth, and yield processes of crop plants. In: Ahuja, L. H., S. A. Saseendran (editors). Response of crops to limited water: Understanding and modeling water stress effects on plant growth processes, Advances in Agricultural Systems Modeling Series 1. ASACSSA: Madison, WI, USA, pp. 301-355.

Rad, M. R. N., M. A. Kadir, M. Y. Rafii, H. Z. E. Jafar and M. Danaee (2013). Gene action for physiological parameters and use of relative water content (RWC) for selection of tolerant and high yield genotypes in $\mathrm{F}_{2}$ population of wheat. Aust. J. Crop Sci. 7: 407-417.

Reynolds, M., Y. Manes, A. Izanloo and P. Langridge (2009). Phenotyping approaches for physiological breeding and gene discovery in wheat. Annals of Applied Biology, 155: 309-320.

Reynolds, M. P., E. Quilligan, P. K. Aggarwal, K. C. Bansal, A. J. Cavalieri, S. C. Chapman, S. M. Chapotin, S. K. Datta, E. Duveiller, K. S. Gill, K. S. V. Jagadish, A. K. Joshi, A. K. Koehler, P. Kosina, S. Krishnan, R. Lafitte, R. S.Mahala, R. Muthurajan, A. H.Paterson, B. M. Prasanna, S. Rakshit, M. W. Rosegrant, I. Sharma, R. P. Singh, S. Sivasankar, V. Vadez, R. Valluru, P.V.V. Prasad and O. P. Yadav (2016). An integrated approach to maintaining cereal productivity under climate change. Global Food Security, 8: 9-18.

Ruan, Y. L., Y. Jin, Y. J. Yang, G. J. Li and J. S. Boyer (2010). Sugar input, metabolism, and signalling mediated by invertase: roles in development, yield potential, and response to drought and heat. Molecular Plant, 3(6): 942-955.

Ruuska, S. A., G. J. Rebetzke, A. F. van Herwaarden, R. A. Richards, N. A. Fettell, L. Tabe and C. L. D. Jenkins (2006). Genotypic variation in water- soluble carbohydrate accumulation in wheat. Funct. Plant Biol. 33: 799-809.

Saba, J., M. Moghadam, K. Ghassemi and M. R. Nishabouri (2010). Genetic properties of drought resistance indices. J. Agricultural Science and Technology, 3: 43-49.

Sanders, G. J. and S. K. Arndt (2012). Osmotic adjustment under drought conditions. In: Aroca, R. (editor). Plant Responses to Drought Stress. Springer, Berlin, Heidelberg, pp. 199-229.

Sattar, A., A. Sher, M. Ijaz, S. Ul-Allah, M. S. Rizwan, M. Hussain, K. Jabran and M. A. Cheema (2020). Terminal drought and heat stress alter physiological and biochemical attributes in flag leaf of bread wheat. Plos One, 15(5): e0232974.

Shearman, V., R. Sylvester-Bradley, R. Scott and M. Foulkes (2005). Physiological processes associated with wheat yield progress in the UK. Crop Sci. 45: 175-185.

Shi, H., B. Wang, P. Yang, Y. Li and F. Miao (2016). Differences in sugar accumulation and mobilization between sequential and nonsequential senescence wheat cultivars under natural and drought conditions. PLoS ONE 11(11): e0166155. doi: 10.1371/journal.pone. 0166155

Thalmann, M. and D. Santelia (2017). Starch as a determinant of plant fitness under abiotic stress. New Phytologist, 214(3): 943-951.

Turhan, E. (2012). Seasonal alteration of sugar metabolism in strawberry (Fragaria $\times$ ananassa) plants during cold-acclimated and non-acclimated stages. African J. Biotechnology, 11(20): 4558-4565.

van Handel, E. (1968). Direct micro determination of sucrose. Analytical Biochemistry, 22(2): 280283.

Villadsen, D., J. H. Rung and T. H. Nielsen (2005). Osmotic stress changes carbohydrate partitioning and fructose-2,6-bisphosphate metabolism in barley leaves. Functional Plant Biology, 32: 1033.

Wang, B., M. Ma, H. Lu, Q. Meng, G. Li and X. Yang (2015). Photosynthesis, sucrose metabolism, and starch accumulation in two NILs of winter wheat. Photosynthesis Research, 126(2-3): 363-373.

Yang, J. and J. Zhang (2006). Grain filling of cereals under soil drying. New Phytol. 169:223-236.

Zhang, P., Y. Liu, M. Li, J. Ma, C. Wang, J. Su and D. Yang (2020). Abscisic acid associated with key enzymes and genes involving in dynamic flux of water soluble carbohydrates in wheat peduncle under terminal drought stress. Plant Physiology and Biochemistry, 151:719-728. 